\title{
On the Role of $\mathrm{CO}_{2}$ in NHC-Catalyzed Oxidation of Aldehydes
}

\author{
Pei-Chen Chiang and Jeffrey W. Bode ${ }^{*}$ \\ Department of Chemistry, University of Pennsylvania, PA 19104, USA and Laboratorium für \\ Organische Chemie, ETH-Zürich, Zürich 8093, Switzerland
}

\begin{abstract}

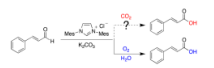

NHC-catalyzed oxidations using carbon dioxide as the stoichiometric oxidant have been carefully investigated. These studies support a secondary role of $\mathrm{CO}_{2}$ in suppressing side reactions and exogenous oxygen as the actual oxidant.
\end{abstract}

Recent communications reported the intriguing oxidation of aldehydes using N-heterocyclic carbenes as catalysts and carbon dioxide as the stoichiometric oxidant (eq 1). ${ }^{1}$ These reports postulated that $\mathrm{CO}_{2}$ is reduced to $\mathrm{CO}$ under catalytic conditions, a process that would be an attractive approach to $\mathrm{CO}_{2}$ fixation provided that an inexpensive aldehyde reaction partner could be identified. At least two different mechanisms have been proposed, one involving addition of the catalyst to the aldehyde to form the nucleophilic Breslow intermediate ${ }^{2}$ and one which proposed direct activation of $\mathrm{CO}_{2}$ by the NHC. Similar reports of NHC-mediated reduction of $\mathrm{CO}_{2}$ with silanes have also generated considerable interest. ${ }^{3}$

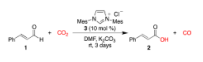

We were particularly intrigued with these findings as they were contrary to the usual chemistry of NHC-catalyzed reactions of $\alpha$-ketoacids, which generate aldehydes and $\mathrm{CO}_{2} \cdot{ }^{4}$ One postulated mechanism involved oxygen atom transfer from $\mathrm{CO}_{2}$ to the aldehyde, a process that is counterintuitive and thermodynamically questionable. ${ }^{5}$ Given our interest in the chemistry of NHC catalysis and the current importance of new catalytic methods for $\mathrm{CO}_{2}$ fixation, ${ }^{3,6}$ we have investigated these reactions further. Through these extensive studies, we conclude that the actual oxidant in these reactions is exogenous oxygen. ${ }^{7,8}$

Our studies began with a careful investigation of the $\mathrm{CO}_{2}$ fixation reaction with the goal of using labelled $\mathrm{CO}_{2}$ as a mechistic probe. Despite dozens of attempts, we were unable to reproduce the reported yields and observations of either Zhang (entries 1-3) on the oxidation of freshly purified cinnamaldehye to cinnamic acid or those Nair on the oxidation of either cinnamaldehyde or para-fluorobenzaldehyde (entry 4 and Supporting Information). ${ }^{9,10}$ After extensive optimization, we found that reproducible formation of cinnamic acid could be achieved under slightly modified Zhang conditions: with $5 \mathrm{~mol} \% \mathrm{IMesCl}(\mathbf{3})$ and 2 equiv $\mathrm{K}_{2} \mathrm{CO}_{3}$ in DMF (entries 5-8). Rigorously dried reaction conditions gave lower yields or irreproducible production of cinnamic acid, which was overcome by the addition of a small

bode@org.chem.ethz.ch.

Supporting Information Available. Experimental procedures and characterization data for all compounds. This material is available free of charge via the Internet at http://pubs.acs.org. 
amount of water ( 1 equiv). ${ }^{8,11}$ To be consistent with Zhang's experiments, we also attempted the reactions for 3 days, which gave slightly higher conversions under all conditions (entry 6). Higher concentration did not provide improved results due to competing dimerization and other side reactions (entry 7). A more extensive list of reaction conditions attempted can be found in the Supporting Information. Unpurified NMR spectra from the reaction mixtures under various atmospheres show clean formation of the acid under air, trace conversion under $\mathrm{CO}_{2}$, and the formation of byproducts under $\mathrm{N}_{2}$ or vacuum. ${ }^{12}$

Our studies confirmed that $\mathrm{IMesCl}(3)$ was essential for formation of the carboxylic acid product; only trace amounts of cinnamic acid were observed in its absence (entry 8).

Triazolium precatalysts favored the formation of hydrocinnamic acid via the known internal redox reaction (entry 9). ${ }^{13}$ The increased formation of hydrocinnamic acid under $\mathrm{CO}_{2}$ is likely due to the formation of carbonic acid that serves as the proton source for $\beta$ protonation. Thiamine, a thiazolium salt, did not give significant amounts of any product (entry 10). Control experiments and careful analysis of the reaction mixtures and products excluded a Cannizzarro-type reaction ${ }^{14}$ as the origin of the cinnamic acid.

The use of air as an oxidant in NHC-catalyzed oxidations of electron-deficient aldehydes to acids and esters has been previously reported by Yoshida using a slightly different imidazolium catalyst. ${ }^{8}$ Their mechanistic proposal invokes the formation of an acyl azolium, which undergoes esterification or hydrolysis. This mechanism is consistent with numerous reports of NHC-catalyzed oxidative esterification of aldehydes with oxidants including azobenzene, ${ }^{15}$ diphenoquinone, ${ }^{16}$ and $\mathrm{MnO}_{2} \cdot{ }^{17}$ To test if our observations followed this proposal, we conducted the reaction under air in the presence of $\mathrm{MeOH}$; to our surprise only the acid, rather than the expected ester was detected (entry 11). In contrast, the use of transazobenzene as the oxidant afforded cinnamic acid in the presence of water (entry 12) and methyl cinnamate in the presence of $\mathrm{MeOH}$ (entry 13). These observations indicate that under these conditions the oxidation occurs by addition of the NHC-aldehyde complex to molecular oxygen rather than oxidation of the Breslow intermediate to the acyl azolium. ${ }^{18}$

The only experimental observation of both Zhang and Nair that is not consistent with exogenous air acting as the oxidant is their detection of $\mathrm{CO}$ at the completion of the reaction. According to the experimental procedures, this was achieved by injecting the residual gas in the ballon of $\mathrm{CO}_{2}$ into a solution of $\mathrm{PdCl}_{2}$ in acidic water. After $2 \mathrm{hr}$ of stirring, the formation of $\mathrm{Pd}$ black was taken as an indication that $\mathrm{CO}$ was present in the reaction atmosphere. The long reaction times needed for formation of Pd black suggested to us that factors other than $\mathrm{CO}$ may be responsible for its formation. ${ }^{19}$

Although all of these results strongly suggested that $\mathrm{CO}_{2}$ was not playing a direct role in the reaction, we consistently noted that reactions performed under a $\mathrm{CO}_{2}$ atmosphere were cleaner, albeit with lower conversion, than those conducted under $\mathrm{N}_{2}$ or in completely degassed solvents. We postulated that $\mathrm{CO}_{2}$ played a role in reducing the formation of side products, possibly by attenuating the activity of the N-heterocyclic carbenes. ${ }^{20}$ This could deter, for example, the formation of benzoin, ${ }^{21}$ Stetter, ${ }^{22}$ or especially $\gamma$-lactone products ${ }^{23}$ that could be the origin of the messy reaction mixtures observed when conducted under a $\mathrm{N}_{2}$ atmosphere. To test this hypothesis, we examined the effect of $\mathrm{CO}_{2}$ on a different $\mathrm{NHC}$ catalyzed reaction, the formation of cyclopentenes from the same substrate (cinnamaldehyde, $\mathbf{1}$ ) and chalcone $(\mathbf{8})$ in the presence of either imidazolium or triazolium precatalysts (Table 2). ${ }^{24}$ These experiments revealed a pronounced rate deceleration in the presence of $\mathrm{CO}_{2}$, diminishing product formation but without causing the formation of side products. This effect was also observed on the oxidation of cinnamaldehyde using azobenzene under $\mathrm{CO}_{2}$ (Table 1 , entry 12). 
We have previously found that cinnamaldehydes are particularly prone to air oxidation in the presence of NHC-catalysts. ${ }^{13 a}$ To confirm this, we briefly explored the application of the open-air oxidation conditions to other substrate classes (Scheme 1).

In general, we observed results similar to the reported $\mathrm{CO}_{2}$ conditions: cinnamaldehyde gave quantitative yield of the corresponding acid and reasonable isolated yields of carboxylic acids were obtained from simple aromatic aldehydes. Aliphatic and sterically hindered aldehydes gave lower conversions. These observations are consistent with a number of reports of NHC-catalyzed oxidations of aldehydes with air or added stoichiometric oxidants. ${ }^{7,8,15-17}$

In light of these investigations, we conclude that the apparent NHC-catalyzed oxidation of aldehydes with $\mathrm{CO}_{2}$ actually involves exogenous $\mathrm{O}_{2}$ as the stoichiometric oxidant. The observed effect of $\mathrm{CO}_{2}$ lies in a reduction of the side products formed by aldehyde dimerization or oligomerization under the reaction conditions.

\section{Supplementary Material}

Refer to Web version on PubMed Central for supplementary material.

\section{Acknowledgments}

This work was supported by NIH R01-079339 and ETH-Zürich. P.-C.C. is grateful to the government of Taiwan for a predoctoral fellowship.

\section{References}

1. (a) Gu L, Zhang Y. J. Am. Chem. Soc. 2010; 132:914-915. [PubMed: 20039670] (b) Nair V, Varghese V, Paul RR, Jose A, Sinu CR, Menon RS. Org. Lett. 2010; 12:2653-2655. [PubMed: 20446713]

2. Breslow R. J. Am. Chem. Soc. 1958; 80:3719-3726.

3. (a) Riduan SN, Zhang Y, Ying JY. Angew. Chem., Int. Ed. 2009; 48:3322-3325.(b) Huang F, Lu G, Zhao L, Li H, Wang Z-X. J. Am. Chem. Soc. 2010; 132:12388-12396. [PubMed: 20707349]

4. For a recent mechanistic study, see: Gonzalez-James OM, Singleton DA. J. Am. Chem. Soc. 2010; 132:6896-6897. [PubMed: 20433168]

5. Jiang Z, Xiao T, Kuznetsov VL, Edwards PP. Phil. Trans. R. Soc. A. 2010; 368:3343-3364. [PubMed: 20566515]

6. (a) Kayaki Y, Yamamoto M, Ikariya T. Angew. Chem., Int. Ed. 2009; 48:4194-4197.(b) Mak XY, Ciccolini RP, Robinson JM, Tester JW, Danheiser RL. J. Org. Chem. 2009; 74:9381-9387. [PubMed: 19921799] (c) Zhou H, Zhang W-Z, Liu C-H, Qu J-P, Lu X-B. J. Org. Chem. 2008; 73:8039-8044. [PubMed: 18788780] (d) Tommasi I, Sorrentino F. Tetrahedron Lett. 2009; 50:104107.

7. Lin L, Li Y, Du W, Deng W-P. Tetrahedron Lett. 2010; 51:3571-3574.

8. Yoshida M, Katagiri Y, Zhu W-B, Shishido K. Org. Biomol. Chem. 2009; 7:4062-4066. [PubMed: 19763312]

9. Cinnamaldehyde was purified by vacuum distillation prior to use. Solvents were obtained from a solvent drying system.

10. Zhang reports that commerical aldehydes were used without prior purification. Under these conditions, we have observed slightly greater amounts of oxidized products under all conditions tested.

11. (a) Lim M, Yoon CM, An G, Rhee H. Tetrahedron Lett. 2007; 48:3835-3839.(b) An G, Ahn H, De Castro KA, Rhee H. Synthesis. 2010:477-485.

12. Atmosphere exchange for the reactions shown in Figure 1 was performed by freeze-pump-thaw and reaction were conducted in a sealed tube. 
13. (a) Sohn SS, Bode JW. Org. Lett. 2005; 7:3873-3876. [PubMed: 16119920] (b) Sohn SS, Bode JW. Angew. Chem., Int. Ed. 2006; 45:6021-6024.(c) Reynolds NT, Read de Alaniz J, Rovis T. J. Am. Chem. Soc. 2004; 126:9518-9519. [PubMed: 15291537]

14. (a) Cannizzaro S. Liebigs Ann. Chem. 1853; 88:129-130.(b) Sreenivasulu M, Kumar KA, Reddy KS, Kumar KS, Kumar PR, Chandrasekhar KB, Pal M. Tetrahedron Lett. 2011; 52:727-732.

15. (a) Inoue H, Higashiura K. J. Chem. Soc., Chem. Commun. 1980:549-550.(b) Noonan C, Baragwanath L, Connon SJ. Tetrahedron Lett. 2008; 49:4003-4006.(c) Rose CA, Zeitler K. Org. Lett. 2010; 12:4552-4555. [PubMed: 20863078]

16. (a) Guin J, De Sarkar S, Grimme S, Studer A. Angew. Chem., Int. Ed. 2008; 47:8727-8730.(b) De Sarkar S, Grimme S, Studer A. J. Am. Chem. Soc. 2010; 132:1190-1191. [PubMed: 20055393]

17. Maki BE, Chan A, Phillips EM, Scheidt KA. Tetrahedron. 2009; 65:3102-3109. [PubMed: 20161230]

18. After the submission of this manuscript, two publications on NHC-catalyzed oxidations of aldehydes with air have appeared. These reports confirm that oxidation occurs by direct addition of an NHC-aldehyde complex to molecular oxygen: (a) Maji B, Vedachalan S, Ge X, Cai S, Liu X-W. J. Org. Chem. 2011; 76 (b) Park JH, Bhilare SV, Youn SW. Org. Lett. 2011; 13

19. In our experience, this is a good test if Pd-black forms within minutes but is less reliable with prolonged reaction times, particularly if metal needles or syringes are used in the reaction setup.

20. (a) Kuhn N, Al-Sheikh A. Coord. Chem. Rev. 2005; 249:829-857.(b) Duong HA, Tekavec TN, Arif AM, Louie J. Chem. Commun. 2004:112-113.(c) Van Ausdall BR, Glass JL, Wiggins KM, Aarif AM, Louie J. J. Org. Chem. 2009; 74:7935-7942. [PubMed: 19775141]

21. Miyashita A, Suzuki Y, Okumura Y, Iwamoto K-i, Higashino T. Chem. Pharm. Bull. 1998; 46:611.

22. Matsumoto Y, Tomioka K. Tetrahedron Lett. 2006; 47:5843-5846.

23. (a) Sohn SS, Rosen EL, Bode JW. J. Am. Chem. Soc. 2004; 126:14370-14371. [PubMed: 15521753] (b) Burstein C, Glorius F. Angew. Chem., Int. Ed. 2004; 43:6205-6208.

24. (a) Chiang P-C, Kaeobamrung J, Bode JW. J. Am. Chem. Soc. 2007; 129:3520-3521. [PubMed: 17335218] (b) Nair V, Vellalath S, Poonoth M, Suresh E. J. Am. Chem. Soc. 2006; 128:87368737. [PubMed: 16819860] 

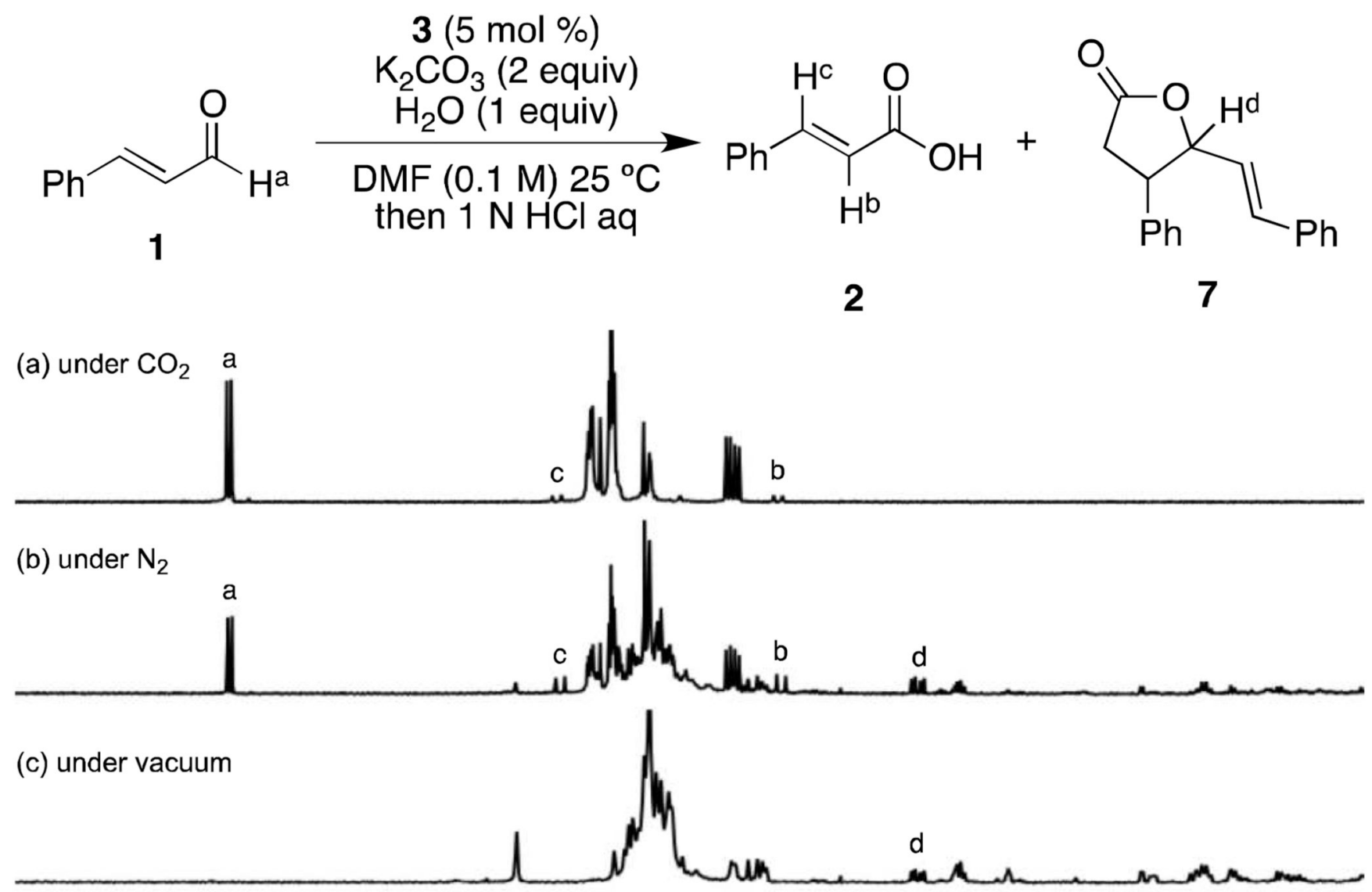

(d) open to air

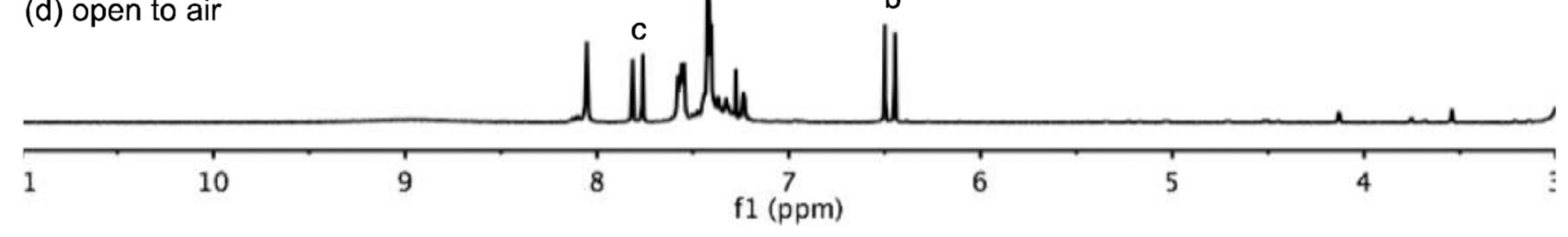

Figure 1.

${ }^{1} \mathrm{H}$ NMR comparison in different atmospheres. 


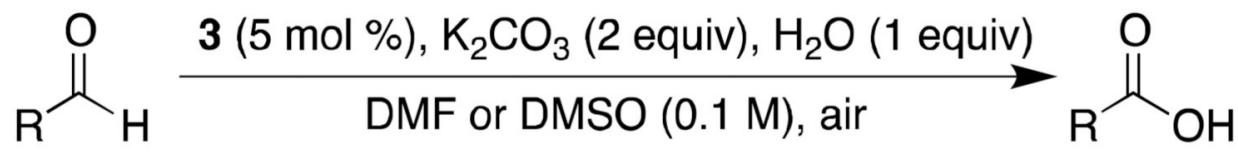<smiles>O=C(O)/C=C/c1ccccc1</smiles>

$2(99 \%)$

DMF, $25^{\circ} \mathrm{C}, 16 \mathrm{~h}$<smiles>O=C(O)c1ccccc1</smiles>

$13(57 \%)$ DMSO, $60{ }^{\circ} \mathrm{C}, 40 \mathrm{~h}$<smiles>O=C(O)c1ccc(Br)cc1</smiles>

$15(55 \%)$ DMSO, $60^{\circ} \mathrm{C}, 40 \mathrm{~h}$<smiles>CCCC#CC(=O)O</smiles>

$10(62 \%)$

DMF, $25^{\circ} \mathrm{C}, 16 \mathrm{~h}$<smiles>COc1ccc(C(=O)O)cc1</smiles>

$14(41 \%)$

DMSO, $60{ }^{\circ} \mathrm{C}, 40 \mathrm{~h}$<smiles>O=C(O)c1ccc(Cl)cc1</smiles>

$16(61 \%)$

DMSO, $60{ }^{\circ} \mathrm{C}, 40 \mathrm{~h}$<smiles>CCCC=CC(=O)O</smiles>

$11(22 \%)^{b}$ DMF, $25{ }^{\circ} \mathrm{C}, 16 \mathrm{~h}$<smiles>CCCCCCC(=O)O</smiles>

$12(21 \%)^{b}$

DMSO, $60{ }^{\circ} \mathrm{C}, 16 \mathrm{~h}$<smiles>O=C(O)c1c(Cl)cccc1Cl</smiles>

$17(25 \%)^{b}$

DMSO, $60{ }^{\circ} \mathrm{C}, 16 \mathrm{~h}$

Scheme 1.

Substrate scope of aerobic oxidation of aldehydes.a

${ }^{\text {a }}$ All of the reactions were carried out in $0.5 \mathrm{mmol}$ scale; isolated yields of pure products after acid-base extraction ${ }^{b} 10 \mathrm{~mol} \% \mathrm{IMesCl}$ was used. 
Table 1

Oxidation of cinnamaldehyde with NHCs.

\begin{tabular}{|c|c|c|c|c|}
\hline 1 & $\begin{array}{r}3(5 \mathrm{~mol} \%) \\
\mathrm{K}_{2} \mathrm{CO}_{3}(2 \text { equiv }), \mathrm{H}_{2} \mathrm{O} \\
\mathrm{DMF}(0.1 \mathrm{M}), \mathrm{CO}_{2} \text { or } \\
25^{\circ} \mathrm{C}, 16 \mathrm{~h} \\
\text { then } 1 \mathrm{~N} \mathrm{HCl}\end{array}$ & $\underset{\text { or air }}{\stackrel{\text { equiv) }}{\longrightarrow}}$ & & \\
\hline entry & conditions & $\mathrm{CO}_{2}{ }^{a}$ & $\mathbf{N}_{2}{ }^{a}$ & air $^{a}$ \\
\hline 1 & dry, $\mathrm{K}_{2} \mathrm{CO}_{3}$ (2 equiv), DMSO & $8 \%$ & $4 \%$ & - \\
\hline 2 & dry, $\mathrm{K}_{2} \mathrm{CO}_{3}$ (2 equiv), DMF & $4 \%$ & $3 \%$ & - \\
\hline 3 & dry, $t$-BuOK ((2 equiv), DMF & $8 \%$ & $45 \%$ & - \\
\hline 4 & dry, DBU (20 mol \%), THF ${ }^{b}$ & $10 \%$ & $20 \%$ & $13 \%$ \\
\hline 5 & as shown in reaction scheme & $14 \%$ & $23 \%$ & $57 \%$ \\
\hline 6 & $0.1 \mathrm{M} / 3$ days & $17 \%$ & $27 \%$ & $64 \%$ \\
\hline 7 & $0.5 \mathrm{M} / 3$ days & $14 \%$ & $40 \%$ & $32 \%$ \\
\hline 8 & without NHC precatalyst & $2 \%$ & $1 \%$ & $0 \%$ \\
\hline 9 & triazolium cat. $4^{c}(5 \mathrm{~mol} \%)$ & $12 \%^{e}$ & $15 \% f$ & - \\
\hline 10 & thiazolium cat. $5^{d}(5 \mathrm{~mol} \%)$ & $5 \%$ & $2 \%$ & $2 \%$ \\
\hline 11 & dry, $\mathrm{MeOH}$ ( 2 equiv) & - & - & $64 \%$ \\
\hline 12 & trans-azobenzene (1.0 equiv) & $21 \%$ & $52 \%$ & - \\
\hline 13 & $\mathrm{MeOH}$ (2 equiv), azobenzene & $0 \% g$ & $0 \% h$ & - \\
\hline
\end{tabular}

${ }^{a}$ See Supporting Information for detailed conditions. Conversion to cinnamic acid 2 was calculated from ${ }^{1} \mathrm{H}$ NMR of crude mixtures.

${ }^{b}$ Purged with a slow stream of gas for 30 min. Hydrocinnamic acid was the major product regardless of reaction atmopsheres.

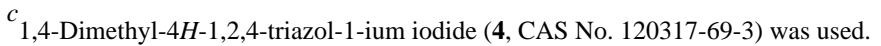

$d_{\text {Thiamine }} \cdot \mathrm{HCl}\left(5\right.$, CAS No. 67-03-8) and 3 equiv $\mathrm{K}_{2} \mathrm{CO}_{3}$ were employed.

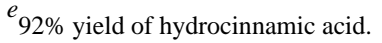

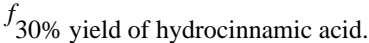

$g_{4 \%}$ yield of methyl cinnamate.

$h_{44 \%}$ yield of methyl cinnamate. 
Table 2

$\mathrm{CO}_{2}$ effect in NHC-catalyzed annulation.

\begin{tabular}{ccc}
\hline & & \\
\hline entry & conditions & yield of cyclopentene \\
\hline 1 & $\mathrm{CO}_{2}, \mathrm{IMesCl}$ & $8 \%$ \\
2 & $\mathrm{~N}_{2}, \mathrm{IMesCl}$ & $59 \%$ \\
3 & $\mathrm{CO}_{2}, \mathrm{RMesCl}$ & $36 \%$ \\
4 & $\mathrm{~N}_{2}, \mathrm{RMesCl}$ & $62 \%$ \\
\hline
\end{tabular}

